\title{
Gamificação como estratégia para o engajamento de estudantes no ensino de commodities: um relato de experiência com alunos do $9^{\circ}$ ano do Ensino Fundamental
}

\section{Daniel Fonseca de Medeiros, Fernando Lucas de Oliveira Farias, Daniel Araújo de Lucena, Charles Andryê Galvão Madeira, José Guilherme da Silva Santa Rosa e Sidney S. Trindade}

\author{
Instituto Metrópole Digital - Universidade Federal do Rio Grande do Norte (UFRN) \\ Av. Sen. Salgado Filho, 3000 - Lagoa Nova, CEP: 59.078-970 - Natal - RN - Brasil \\ \{geodanielprofl, fernandoo.mcp, daniel.fafic\}@gmail.com, charles@imd.ufrn.br, \\ jguilhermesantarosa@gmail.com e sidney@info.ufrn.br
}

Abstract. One of the main challenges currently faced by teachers of basic education is the lack of motivation of students to learn what is taught in the classroom. This reality is not different for the discipline of Geography once students rarely assimilate contents that do not make sense for them. In order to deal with this problem, this paper proposes a gamified model entitled "Geogamification" to be applied with students of the 9th grade of High School. The results of the research indicate that the use of the proposed model provided greater engagement and motivation of the students, being measured through the data obtained with the reaction evaluation applied at the end of the experiment.

Resumo. Um dos principais desafios enfrentados atualmente pelos professores da Educação Básica consiste na desmotivação dos alunos para aprender o que se é ensinado na sala de aula. Na disciplina de Geografia essa realidade não é diferente, pois quando o conteúdo estudado não faz sentido para o aluno, dificilmente ele é assimilado. Neste sentido, o presente artigo tem como objetivo apresentar uma experiência vivenciada pelos alunos do $9^{\circ}$ ano do Ensino Fundamental por meio de uma proposta gamificada intitulada "Geogamification". Os resultados da pesquisa apontam que a utilização do modelo proposto propiciou maior engajamento $e$ motivação dos estudantes, sendo mensurados através dos dados obtidos com a avaliação de reação aplicada ao final do experimento.

\section{Introdução}

A desmotivação dos alunos no processo de ensino e aprendizagem das disciplinas que compõem a Educação Básica vem se constituindo em um dos principais desafios dos professores e das instituições escolares na atualidade [Cavalcante et al. 2016].

Na maioria das vezes, a Geografia ensinada nas escolas geralmente não acompanha as novas descobertas, passando um conhecimento sem significado para o aluno, pois "mantém, ainda, uma prática tradicional, tanto no Ensino Fundamental quanto no Médio. Para a maioria dos alunos, a aprendizagem da Geografia na escola se reduz somente à memorização, sem fazer referência às experiências socioespaciais" [Bomfim 2006]. 
Diante desta situação, torna-se imprescindível buscar soluções para remediá-lo de forma efetiva. Um dos possíveis caminhos existentes na literatura é o da Gamificação no qual busca-se motivar, engajar e, idealmente, modificar positivamente o comportamento de um determinado público-alvo através do uso de recursos e elementos do mundo dos jogos [Deterding 2011].

Em nosso experimento, procuramos na fase de diagnóstico avaliar através de um survey a motivação dos alunos para o aprendizado dos conteúdos de Geografia trabalhados no $9^{\circ}$ ano do ensino fundamental; nesta perspectiva identificamos nas 73 respostas coletadas que, 45,2\% dos participantes afirmaram não gostar da disciplina; sendo que 23,3\% afirmaram que depende do assunto, não gostando dos conteúdos trabalhados no $9^{\circ}$ ano; enquanto $20,5 \%$ afirmam categoricamente não gostar da disciplina.

Em análise as principais respostas coletadas nas questões discursivas, acerca da percepção dos alunos participantes do estudo sobre as aulas de Geografia; identificamos que parte deles classificam as aulas como: "cansativas, pouco interessantes, causam distração e pouco relacionadas ao cotidiano".

Não obstante, visando reverter esse cenário de desmotivação e pouco engajamento dos estudantes com as aulas de Geografia; selecionamos o framework para gamificação Octalysis que forneceu apoio a solução "Geogamification", por permitir estabelecer uma relação interessante entre as formas da motivação humana e os elementos e técnicas de jogos para delinear caminhos que permitam aumentar a probabilidade de modificar positivamente o comportamento dos alunos, criando uma experiência lúdica que torne os alunos mais engajados.

O framework Octalysis foi desenvolvido por Yu-Kai Chou e objetiva relacionar quais os tipos de motivação engajam as pessoas no trabalho, nos jogos e em atividades comuns do dia-adia. Ele é comumente utilizado como uma bússola no processo de gamificação, principalmente auxiliando no entendimento do cenário inicial em que está trabalhando e na proposta desejada [Chou 2015].

Por conseguinte, a proposta de gamificação aqui intitulada Geogamification, é usada como estratégia motivacional para os alunos de Geografia do $9^{\circ}$ ano do Ensino Fundamental que estão estudando Commodities, Modais de Transporte e Fluxo de Mercadorias. Os resultados obtidos através dos indicadores de engajamento estudantil demonstram maior engajamento dos estudantes para aprendizado destes conteúdos através da estratégia proposta neste estudo.

O trabalho está organizado da seguinte forma: na Seção 2 são apresentados trabalhos relacionados a utilização de técnicas de gamificação como estratégia para engajamento de estudantes; a Seção 3 apresenta a metodologia utilizada no desenvolvimento do trabalho; a Seção 4 são apresentados os conceitos relacionados à gamificação e seus elementos; a Seção 5 detalha a Prototipação do "Geogamification" em 4 etapas; a Seção 6 apresenta os resultados obtidos durante o experimento e discussão sobre o engajamento dos estudantes, por fim, a Seção 7 detalha as Considerações Finais e apresenta possibilidades para Trabalhos Futuros. 
VII Congresso Brasileiro de Informática na Educação (CBIE 2018)

Anais do XXIV Workshop de Informática na Escola (WIE 2018)

\section{Trabalhos Relacionados}

Dentre os trabalhos relacionados, podemos citar o estudo de Toda et al. (2016) que apresenta um processo de gamificação para a disciplina de Bioquímica. Os resultados encontrados demonstram que o método gamificado foi considerado divertido e interessante pelos alunos do curso.

Mebs (2017), descreve a utilização do jogo Multicraft para trabalhar com seus alunos o espaço geográfico e as diferentes paisagens; com ênfase nas transformações realizadas pelos seres humanos por meio das atividades econômicas, buscando atender suas necessidades.

Lima (2015), descreve a criação de um núcleo com a proposta de levar games para dentro da escola como ferramenta de ensino, apresentando o uso de jogos para trabalhar conceitos de paisagens históricas e organização interna de cidades.

Carneiro e Backes (2017), propõem em seu estudo que alunos com o hábito de jogar videogame apresentam maior predisposição para o aprendizado de conceitos cartográficos e na interpretação de paisagens através dos cenários e imagens históricas.

Neste sentido, a abordagem proposta utiliza elementos e técnicas de jogos no processo de gamificação; como estratégia para engajamento dos estudantes no aprendizado de Commodities, Modais de Transporte e Fluxo de Mercadorias através de um artefato pedagógico intitulado "Geogamification", diferenciando-se dos trabalhos relacionados por trabalhar de forma lúdica e interativa; conhecimentos, habilidades, atitudes e competências previstas na Base Nacional Comum Curricular (BNCC $\left.{ }^{1}\right)$ para conteúdos de Geografia do $9^{\circ}$ ano do ensino fundamental.

\section{Metodologia}

A realização do estudo seguiu inicialmente uma abordagem qualitativa no que diz respeito à compreensão dos fatores relacionados ao baixo engajamento dos estudantes com a disciplina de Geografia; investigados através de um questionário semiestruturado. Para Minayo (2001), a pesquisa qualitativa trabalha com o universo de significados, motivos, aspirações, valores e atitudes; promovendo maior enfoque na interpretação do objeto, proximidade do pesquisador em relação aos fenômenos estudados, não se restringindo à operacionalização de variáveis.

O estudo seguiu aspecto quantitativo na construção da proposta de gamificação baseada na metodologia do Design Thinking; o qual é caracterizado por ser um processo focado no entendimento da problemática de forma aprofundada para só então se propor soluções que a resolvam de forma efetiva. Isso é alcançado através de uma imersão profunda no contexto do problema, buscando as verdadeiras raízes da questão investigada. A partir daí projeta-se uma solução que possa resolvê-la com eficácia [Vianna et al. 2012].

Nosso experimento tem como objetivo principal, motivar e dar significado ao aprendizado de conteúdos relacionados a disciplina de Geografia; que neste relato de experiência foi sobre commodities, modais de transporte e o fluxo de mercadorias, a fim de permitir que os estudantes saibam como suas escolhas podem influenciar (positiva ou negativamente) o desempenho da sua produção no país, a estruturação da proposta seguiu as etapas constantes na Tabela 1.

${ }^{1}$ Disponível em: <http://bit.ly/2takwn9> Acesso em: 19 jun. 2018 
VII Congresso Brasileiro de Informática na Educação (CBIE 2018)

Anais do XXIV Workshop de Informática na Escola (WIE 2018)

Tabela 1. Etapas do Design Thinking na concepção da proposta "Geogamification"

\begin{tabular}{|c|c|c|}
\hline Etapa & Descrição & Resultado Obtido \\
\hline Imersão & $\begin{array}{l}\text { Estruturamos uma pesquisa semiestruturada } \\
\text { através de um survey, aplicado em três } \\
\text { turmas do } 9^{\circ} \text { ano do ensino fundamental; que } \\
\text { procurou diagnosticar a percepção dos } \\
\text { alunos, acerca das aulas de Geografia para } \\
\text { compreender e identificar a proporção de } \\
\text { alunos que se classificam motivados com a } \\
\text { disciplina; bem como àqueles que sentem-se } \\
\text { desmotivados e elencando os principais } \\
\text { motivos para incidência de frustração, a fim } \\
\text { de subsidiar estratégias a serem delineadas na } \\
\text { próxima etapa para que seja possível } \\
\text { modificar positivamente o comportamento } \\
\text { destes alunos, partindo dos seus interesses } \\
\text { coletados na pesquisa realizada na fase de } \\
\text { diagnóstico. }\end{array}$ & 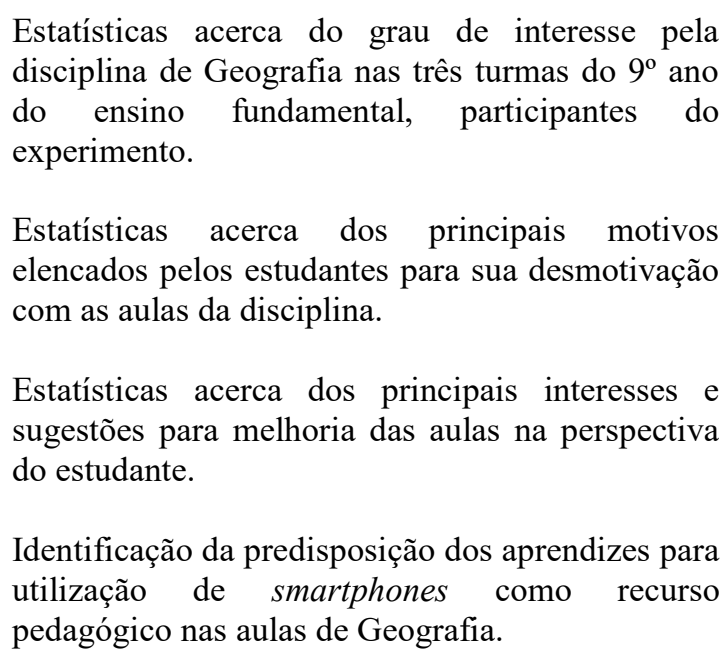 \\
\hline Ideação & $\begin{array}{l}\text { Utilizando o framework Octalysis em seu } \\
\text { nível mais básico; procuramos analisar e } \\
\text { postular os aspectos motivacionais } \\
\text { norteadores para que seja possível delinear } \\
\text { uma estratégia baseada em gamificação onde } \\
\text { seja possível engajar e dar significado ao } \\
\text { aprendizado de conteúdos relacionados a } \\
\text { Geografia para os participantes do } \\
\text { experimento. }\end{array}$ & $\begin{array}{l}\text { Identificação dos principais tipos de motivação } \\
\text { intrínseca e extrínseca que engajam os estudantes } \\
\text { participantes do experimento, Tabela } 2 \text {. } \\
\text { Definição dos principais objetivos da gamificação. } \\
\text { Seleção das mecânicas e técnicas de jogos que } \\
\text { serão utilizadas na solução gamificada a ser } \\
\text { desenvolvida, Tabela } 2 \text {. }\end{array}$ \\
\hline Prototipação & $\begin{array}{l}\text { Após identificados os motivadores } \\
\text { extrínsecos e intrínsecos; selecionadas as } \\
\text { mecânicas e técnicas de jogos a serem } \\
\text { incorporadas a solução gamificada; iniciamos } \\
\text { a prototipação da solução "Geogamification" } \\
\text { que foi estruturada em quatro etapas. Em } \\
\text { seguida, o protótipo desenvolvido foi } \\
\text { disponibilizado para os alunos participante } \\
\text { durante as aulas sobre Commodities, Modais } \\
\text { de Transporte e Fluxo de Mercadorias, em } \\
\text { seguida, realizamos uma avaliação de reação } \\
\text { para identificar a percepção e colher } \\
\text { feedback dos estudantes acerca da proposta } \\
\text { gamificada apresentada. }\end{array}$ & $\begin{array}{l}\text { Criação da versão beta do objeto de aprendizagem } \\
\text { "Geogamification", descrito na Tabela } 4 . \\
\text { Criação e execução da avaliação de reação do } \\
\text { modelo proposto. } \\
\text { Quantificação e análise dos indicadores de } \\
\text { engajamento estudantil dos participantes do } \\
\text { experimento, Figura } 1 \text { e Figura } 2 \text {. }\end{array}$ \\
\hline
\end{tabular}

Por conseguinte, após análise dos dados coletados na fase de imersão do Design Thinking fruto do questionário de diagnóstico aplicado no início do experimento; identificamos os principais motivos elencados pelos estudantes para sua desmotivação com as aulas de Geografia, bem como interesses e sugestões de melhorias para as aulas; servindo de insumo para definição

${ }^{2}$ Disponível em: <http://bit.ly/2K7flvI > Acesso em: 21 jun. 2018 
VII Congresso Brasileiro de Informática na Educação (CBIE 2018)

Anais do XXIV Workshop de Informática na Escola (WIE 2018)

dos principais ativadores motivacionais, mecânicas e técnicas de jogos selecionados na fase de ideação da proposta; sendo utilizados na primeira versão da solução gamificada "Geogamification" prototipada na última fase da metodologia selecionada, conforme ilustrado na Tabela 2 .

Tabela 2. Classificação das mecânicas e técnicas de jogos do framework Octalysis utilizadas na primeira versão do "Geogamification"

\begin{tabular}{|c|c|c|}
\hline Ativador de motivação & Mecânica de jogo & Técnica de jogo \\
\hline Significado Épico & Missões & Narrativa \\
\hline Desenvolvimento & Experiência e Habilidades & Pontos e Símbolos de Conquista \\
\hline Imprevisibilidade & Memória e Forçar a Sorte & Escolha Brilhante \\
\hline Propriedade & Prêmios & Almoço Conquistado \\
\hline
\end{tabular}

\section{Gamificação}

Nesta seção serão apresentados os conceitos de gamificação; seus elementos e estratégias direcionadas a proporcionar maior motivação e engajamento dos estudantes, bem como descrição do planejamento da gamificação aplicada na proposta "Geogamification".

\subsection{Conceito de Gamificação}

O termo gamificação pode ser compreendido em linhas gerais como a utilização dos elementos de jogos e game design fora do contexto de jogos. Segundo Vianna et al. (2013) é o uso de mecânicas de jogos em contextos diversos, com o objetivo de incrementar a participação e gerar engajamento e comprometimento por parte de potenciais usuários. Kapp (apud Borges et al. 2013), define como a aplicação de elementos utilizados no desenvolvimento de jogos eletrônicos tais como: estética, mecânicas e dinâmicas; em outros contextos não relacionados a jogos.

\subsection{Planejando a Gamificação}

O processo de gamificação proposto utilizou a metodologia do Design Thinking para melhor compreensão dos aspectos motivacionais relacionados ao interesse dos alunos pelas aulas de Geografia.

Neste sentido, a identificação de comportamentos relacionados a baixa motivação, ver Tabela 5, constituíram como principal fator para construção de uma proposta lúdica, interativa, incorporando elementos e técnicas de jogos; a fim de trabalhar com conteúdos do $9^{\circ}$ do ensino fundamental que tornassem os estudantes protagonistas na construção do seu conhecimento. Assim como, permitissem trabalhar conhecimentos, habilidades, atitudes e competências previstas na BNCC, conforme Tabela 3. 
VII Congresso Brasileiro de Informática na Educação (CBIE 2018)

Anais do XXIV Workshop de Informática na Escola (WIE 2018)

Tabela 3. Conhecimentos, Habilidades, Atitudes e Competências da BNCC $^{3}$ trabalhadas no experimento utilizando o "Geogamification"

\begin{tabular}{|c|c|c|c|c|}
\hline Conhecimentos & Habilidades & Atitudes & Competências & $\begin{array}{c}\text { Etapa } \\
\text { Geogamification }\end{array}$ \\
\hline \multirow[b]{2}{*}{ Commodities } & \multirow{2}{*}{$\begin{array}{l}\text { (EF09GE02) } \\
\text { (EF09GE12) } \\
\text { (EF09GE13) }\end{array}$} & \multirow{2}{*}{$\begin{array}{l}\text { Relacionar as } \\
\text { cadeias industriais e } \\
\text { inovação no uso dos } \\
\text { recursos naturais e } \\
\text { matérias-primas. }\end{array}$} & \multirow{4}{*}{$\begin{array}{l}\text { Estabelecer conexões entre } \\
\text { diferentes temas do conhecimento } \\
\text { geográfico, reconhecendo a } \\
\text { importância dos objetos técnicos } \\
\text { para a compreensão das formas } \\
\text { como os seres humanos fazem uso } \\
\text { dos recursos da natureza ao longo } \\
\text { da história; } \\
\text { Desenvolver e utilizar processos, } \\
\text { práticas e procedimentos de } \\
\text { investigação para compreender o } \\
\text { mundo natural, social, econômico, } \\
\text { político e o meio técnico- } \\
\text { científico e informacional; avaliar } \\
\text { ações e propor perguntas e } \\
\text { soluções (inclusive tecnológicas) } \\
\text { para questões que requerem } \\
\text { conhecimentos científicos da } \\
\text { Geografia. }\end{array}$} & $\begin{array}{l}\text { 1. Selecionando } \\
\text { a Commodity }\end{array}$ \\
\hline & & & & $\begin{array}{l}\text { 2. Selecionando } \\
\text { a Região } \\
\text { Brasileira de } \\
\text { Produção }\end{array}$ \\
\hline \multirow{2}{*}{$\begin{array}{l}\text { Modais de } \\
\text { Transporte e } \\
\text { Fluxo de } \\
\text { Mercadorias }\end{array}$} & \multirow[b]{2}{*}{$\begin{array}{l}\text { (EF09GE10) } \\
\text { (EF09GE11) }\end{array}$} & \multirow{2}{*}{$\begin{array}{l}\text { Contextualizar a } \\
\text { integração mundial } \\
\text { e suas } \\
\text { interpretações: } \\
\text { globalização } \\
\text { mundialização; } \\
\\
\text { Relacionar as } \\
\text { transformações do } \\
\text { espaço na sociedade } \\
\text { urbano-industrial. }\end{array}$} & & $\begin{array}{l}\text { 3.Selecionando o } \\
\text { Modal de } \\
\text { Transporte }\end{array}$ \\
\hline & & & & $\begin{array}{l}\text { 4. Avaliando os } \\
\text { Custos e Lucros } \\
\text { com Produção }\end{array}$ \\
\hline
\end{tabular}

A partir dos conhecimentos, habilidades, atitudes e competências dispostos na Tabela 3; foram estabelecidos os objetivos iniciais do processo de gamificação da disciplina, a fim de alterar o baixo quadro de motivação e engajamento identificados nos estudantes na fase de diagnóstico; inclusive permitindo determinar se as alterações planejadas foram eficazes na promoção de mudanças no perfil de motivação dos aprendizes. Eles são os seguintes:

- Ampliar a participação e aprendizagem ativa dos alunos nas aulas de Geografia, principalmente na execução de atividades e trabalhos colaborativos que visam desenvolver o pensamento crítico, visão holística e contextualização dos assuntos disseminados em sala de aula;

- Reduzir a desmotivação dos alunos com as aulas de Geografia.

\section{Prototipação do "Geogamification" em 4 etapas}

A proposta "Geogamification" foi prototipada visando disponibilizar na primeira etapa, uma sequência de decisões relacionadas a seleção da commodity que cada grupo de estudantes irá administrar; enquanto na segunda etapa os estudantes deverão selecionar a região brasileira de produção levando em consideração a vantajosidade e lucratividade para desenvolvimento da commodity na região escolhida, desta forma, o aluno deverá manifestar a atitude de relacionar as cadeias industriais e inovação no uso dos recursos naturais e matérias-primas prevista na BNCC.

${ }^{3}$ Disponível em: <http://bit.ly/2takwn9> Acesso em: 19 jun. 2018 
VII Congresso Brasileiro de Informática na Educação (CBIE 2018)

Anais do XXIV Workshop de Informática na Escola (WIE 2018)

Tabela 4. Prototipação do "Geogamification" em 4 etapas ${ }^{4}$

\begin{tabular}{|c|c|c|c|}
\hline $\begin{array}{c}\text { Etapa } \\
\text { Geogamification }\end{array}$ & Descrição & Resultados Esperados & $\begin{array}{c}\text { Ferramentas } \\
\text { Utilizadas }\end{array}$ \\
\hline $\begin{array}{l}\text { 1. Selecionando a } \\
\text { Commodity }^{5}\end{array}$ & $\begin{array}{l}\text { Os estudantes são divididos em } \\
\text { grupos; cada grupo é responsável } \\
\text { por administrar uma determinada } \\
\text { produção de commodities, em } \\
\text { nosso experimento foram } \\
\text { disponibilizadas as seis mais } \\
\text { exploradas no Brasil, a saber: } \\
\text { Soja, Petróleo, Boi Gordo, Suco } \\
\text { de Laranja, Ferro e Café. Após } \\
\text { selecionada a commodity, o grupo } \\
\text { tem acesso às informações } \\
\text { detalhadas sobre a mesma que } \\
\text { servirá de insumo para seleção da } \\
\text { região do Brasil onde ocorrerá } \\
\text { sua produção. }\end{array}$ & $\begin{array}{l}\text { Ampliação da participação e } \\
\text { aprendizagem ativa dos alunos. } \\
\text { Relacionar as cadeias industriais } \\
\text { e inovação no uso dos recursos } \\
\text { naturais e matérias-primas. } \\
\text { Estabelecer conexões entre } \\
\text { diferentes temas do conhecimento } \\
\text { geográfico. }\end{array}$ & \multirow{4}{*}{$\begin{array}{c}\text { Google Slides } \\
\text { e } \\
\text { QRcode }\end{array}$} \\
\hline $\begin{array}{l}\text { 2. Selecionando a } \\
\text { Região Brasileira } \\
\text { de Produção }\end{array}$ & $\begin{array}{l}\text { Os grupos decidem sobre a região } \\
\text { mais adequada para } \\
\text { desenvolvimento da commodity } \\
\text { selecionada na etapa anterior. }\end{array}$ & $\begin{array}{l}\text { Compreensão sobre os custos de } \\
\text { produção da commodity, } \\
\text { conforme região do Brasil; } \\
\text { percebendo que decisões erradas } \\
\text { representam maiores custos } \\
\text { operacionais para sua produção. }\end{array}$ & \\
\hline $\begin{array}{c}\text { 3. Selecionando o } \\
\text { Modal de } \\
\text { Transporte }^{6}\end{array}$ & $\begin{array}{l}\text { O grupo escolhe dentro da região } \\
\text { informada na etapa anterior; a } \\
\text { modal de transporte que será } \\
\text { utilizada para translado da } \\
\text { commodity que está sendo } \\
\text { administrada, buscando aquela } \\
\text { que ofereça maior eficácia na } \\
\text { entrega e menor custo com frete. }\end{array}$ & $\begin{array}{l}\text { Identificação da modal de } \\
\text { transporte mais vantajosa para } \\
\text { escoamento da produção da } \\
\text { commodity gerenciada pelo } \\
\text { grupo, combinando variáveis que } \\
\text { assegurem maior eficácia na } \\
\text { entrega e menor custo com frete. }\end{array}$ & \\
\hline $\begin{array}{l}\text { 4. Avaliando os } \\
\text { Custos e Lucros } \\
\text { com Produção }\end{array}$ & $\begin{array}{l}\text { Os grupos contabilizam o total de } \\
\text { despesas que foram despendidas } \\
\text { no decorrer do processo até esta } \\
\text { etapa. São disponibilizados os } \\
\text { valores de frete com os modais de } \\
\text { transporte disponíveis conforme o } \\
\text { peso da carga transportada. }\end{array}$ & $\begin{array}{l}\text { Os grupos deverão ser capazes de } \\
\text { refletir sobre as decisões adotadas } \\
\text { durante o processo de gestão da } \\
\text { commodity, principalmente no } \\
\text { que diz respeito à região de } \\
\text { produção e modal de transporte } \\
\text { selecionada para escoamento das } \\
\text { mercadorias. }\end{array}$ & \\
\hline
\end{tabular}

${ }_{5}^{4}$ Disponível em: <http://bit.ly/2MgLD7d $>$ Acesso em: 19 jun. 2018

5 Commodity é qualquer bem em estado bruto, produzido em escala mundial e com características físicas homogêneas; seja qual for sua origem, geralmente destinado ao comércio externo. Cujo preço é determinado pela oferta e procura internacional.

${ }^{6}$ Modal de transporte é a maneira pela qual uma logística de produtos e pessoas é feita. Ela pode ocorrer pelas rodovias, pela água, ferrovias, por dutos ou pelo ar. 
VII Congresso Brasileiro de Informática na Educação (CBIE 2018)

Anais do XXIV Workshop de Informática na Escola (WIE 2018)

\section{Resultados e Discussões}

Nesta seção, iremos discutir os dados coletados durante as avaliações de diagnóstico e reação realizadas com os estudantes participantes das aulas com a ferramenta "Geogamification", sendo esta última realizada ao término da atividade; o survey teve como objetivo conhecer e mensurar os indicadores de engajamento estudantil após o ensino de commodities, modais de transporte e fluxos de mercadorias utilizando a gamificação como estratégia.

$\mathrm{Na}$ análise dos dados coletados na fase de diagnóstico, os resultados parciais despertaram a atenção do docente da disciplina; principalmente por 45,2\% dos estudantes participantes indicarem motivos para não gostar da disciplina. Neste sentido, foi avaliado no questionário em uma questão discursiva, os principais feedbacks em poucas palavras que os alunos tinham das aulas de Geografia que eles frequentavam; os principais relatos foram consolidados na Tabela 5.

Tabela 5. Percepção dos alunos em poucas palavras sobre as aulas de Geografia

\begin{tabular}{|c|c|c|c|c|c|}
\hline$\#$ & Resposta & \# & Resposta & \# & Resultado \\
\hline 1 & $\begin{array}{l}\text { Cansativas demais, acabo me } \\
\text { distraindo }\end{array}$ & 4 & $\begin{array}{l}\text { Acho que ele ensina } \\
\text { bem, porém não } \\
\text { consigo n prestar } \\
\text { atenção }\end{array}$ & 7 & $\begin{array}{l}\text { São cansativas, mas o } \\
\text { professor é excelente. }\end{array}$ \\
\hline 12 & $\begin{array}{l}\text { Acho legal, mas poderia explicar o } \\
\text { assunto de outras maneiras. Maior } \\
\text { participação da turma. }\end{array}$ & 18 & $\begin{array}{l}\text { São boas, mas } \\
\text { cansativas }\end{array}$ & 32 & $\begin{array}{l}\text { Boas, mas meio cansativas. } \\
\text { Seriam melhores se } \\
\text { tivessem mais esquemas. }\end{array}$ \\
\hline 70 & $\begin{array}{l}\text { As aulas que eu acho melhor são as } \\
\text { aulas em que são dados exemplos, de } \\
\text { forma que o assunto seja relacionado } \\
\text { com uma coisa do dia-a-dia, porque } \\
\text { assim seria uma maneira mais fácil } \\
\text { de se compreender o assunto. }\end{array}$ & 72 & $\begin{array}{l}\text { Gosto muitooo, mas } \\
\text { alguns assuntos são } \\
\text { muito cansativas }\end{array}$ & 73 & $\begin{array}{l}\text { Pouco chamativa, não me } \\
\text { interesso pela aula }\end{array}$ \\
\hline
\end{tabular}

O questionário com os indicadores de engajamento estudantil foi estruturado em nove questões. Cada pergunta aborda um indicador; sendo distribuídos da seguinte forma: (Q1) Autonomia, (Q2) Execução, (Q3) Social, (Q4) Entrega, (Q5) Participação, (Q6) Colaboração, (Q7) Cooperação, (Q8) Questionamento e (Q9) Diversão [Seixas, Gomes e Melo 2015].

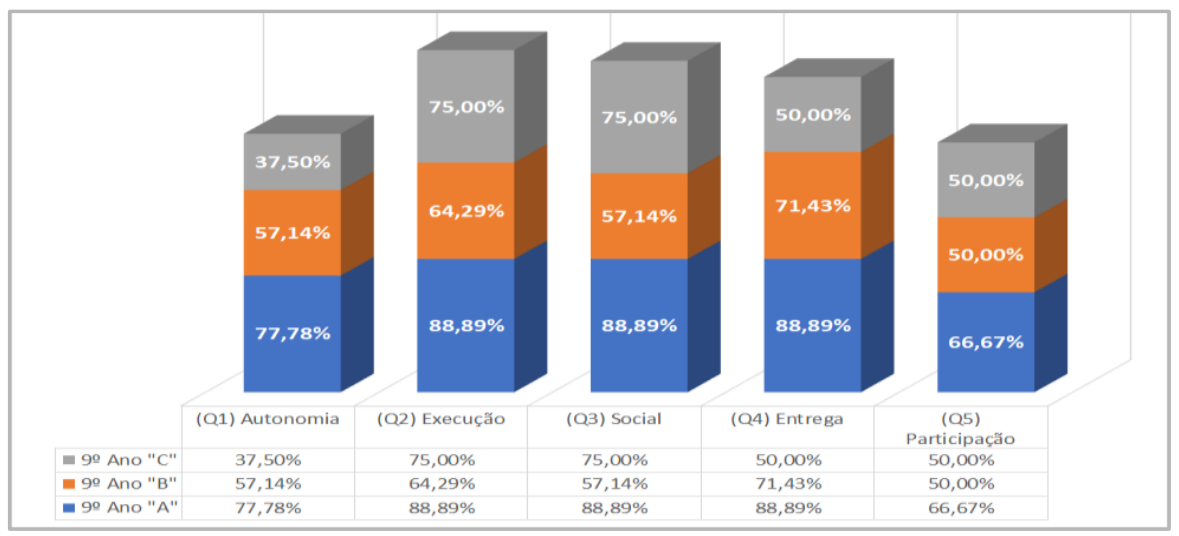

Figura 1. Indicadores de Engajamento Estudantil de todas as turmas 


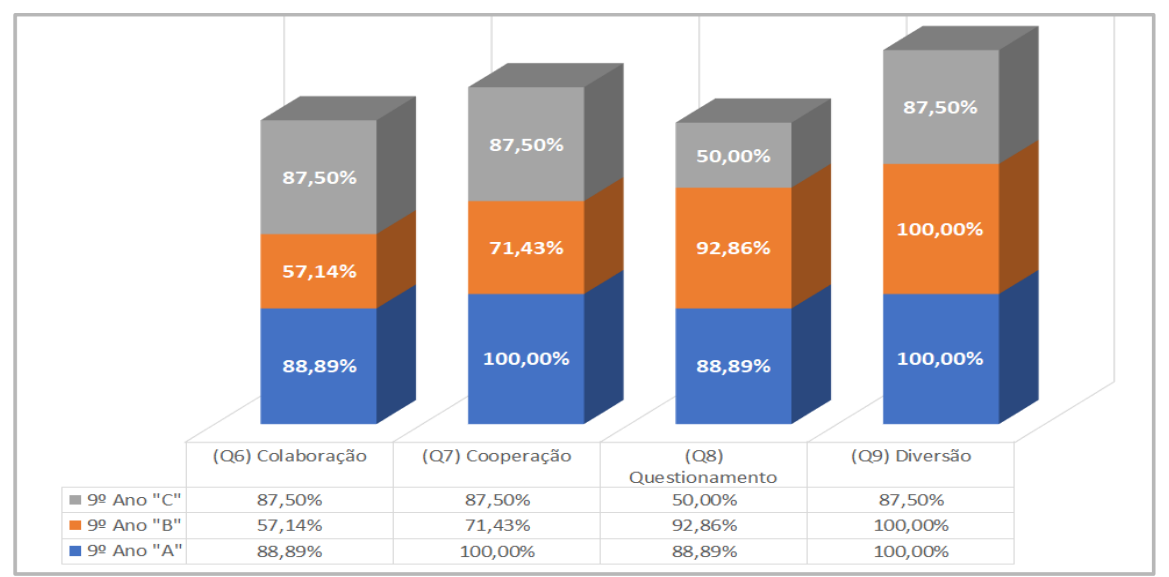

Figura 2. Indicadores de Engajamento Estudantil de todas as turmas

Os indicadores de engajamento estudantil selecionados e ilustrados nas Figuras 1 e 2, foram utilizados visando mensurar quantitativamente o grau de aprendizagem ativa e colaborativa, participação, cooperação, diversão e autonomia manifestada pelos estudantes participantes do experimento envolvendo aplicação da proposta "Geogamification".

A avaliação de reação foi aplicada em três turmas: $9^{\circ}$ Ano "A", $9^{\circ}$ Ano "B" e $9^{\circ}$ Ano "C"; sendo que apenas na turma "A" a proposta foi executada em sua plenitude, enquanto na turma "B" aplicada parcialmente e a turma "C" não tivemos aplicação da abordagem gamificada.

Os resultados obtidos com aplicação da proposta foram bastante significativos e promissores, identificamos que no indicador Q1 (Autonomia) 77,8\% dos alunos da Turma "A" concordam que a atividade proporcionou maior autonomia na tomada de decisões e permitiu estabelecer melhor as conexões dos conteúdos sem a intervenção contínua do professor, enquanto apenas $37,50 \%$ dos estudantes da Turma " $C$ " tiveram essa percepção.

O indicador Q8 (Colaboração) identificamos que 88,89\% dos alunos da Turma "A" concordam que a atividade incentivou o trabalho colaborativo com os colegas de turma, bem como em equipe na construção do conhecimento relacionado a commodities, enquanto apenas $57,14 \%$ dos estudantes da Turma "B" tiveram essa percepção.

O indicador Q9 (Diversão) identificamos que 100,00\% dos alunos das Turma "A" e "B" concordam que a abordagem realizada pelo professor com "Geogamification" durante a apresentação dos conteúdos relacionados a commodities, modais de transporte e fluxo de mercadorias foi divertida, enquanto $87,50 \%$ dos alunos da Turma "C" tiveram essa percepção.

Neste aspecto, alguns alunos reportaram nas observações da avaliação de reação, o seguinte: "Você poderia propor mais dinâmicas como feita nas micro empresas de commodities, professor!", "Ótimo assunto com ótima apresentação, tudo muito divertido e educativo", "Gostei do modo que trabalhou o assunto commodities, me ajudou bastante na hora prova e 'fixou' melhor na minha mente".

\section{Considerações finais}

Percebemos que os alunos têm interesse em aprender. Contudo, a distância que existe entre os conceitos ensinados em sala de aula e a realidade do dia-a-dia dos estudantes é algo característico das aulas tradicionais. 
VII Congresso Brasileiro de Informática na Educação (CBIE 2018)

Anais do XXIV Workshop de Informática na Escola (WIE 2018)

Neste sentido, a proposta gamificada intitulada "Geogamification" demonstrou-se bastante promissora pela capacidade de promover o engajamento estudantil, proporcionado pelo aprendizado ativo, lúdico, interativo, colaborativo e com significado para o aluno, apoiado pela utilização criativa dos smartphones dos aprendizes como artefato pedagógico; pretendemos para trabalhos futuros utilizando o Design Thinking, promover o aprimoramento contínuo da proposta, baseado nas sugestões de melhoria coletadas perante os estudantes e ajustes progressivos nas mecânicas e técnicas de jogo incorporadas à proposta.

\section{Referências}

Borges, Simone de S.; Reis, Helena M.; Durelli, Vinicius H. S.; Bittencourt, Ig I.; Jaques, Patricia A; Isotani, Seiji. Gamificação Aplicada à Educação: Um Mapeamento Sistemático. In: Anais do XXIV Simpósio Brasileiro de Informática na Educação (SBIE 2013), p. 234243. DOI: 10.5753/CBIE.SBIE.2013.234.

Carneiro, Eduardo Lorini; Backes, Luciana. O uso de videogame como recurso didático no ensino de Geografia. Sefic: UNILASALLE, Canoas, 2017.

Cavalcante, Márcio Balbino et al. O ensino da Geografia sob um enfoque motivador. Gaia Scientia, João Pessoa, v. 10, p.138-150, 2016.

Chou, Y. kai. Gamification in education: top ten gamification case studies that will change our future, 2015.

Deterding, S., Dixon, D., Khaled, R., and Nacke, L. (2011). From game design elements to gamefulness: Defining "gamification". In Proceedings of the 15th International Academic MindTrek Conference: Envisioning Future Media Environments, MindTrek'11, pages 9-15, New York, NY, USA. ACM

Kapp, K. M. (2012) The Gamification of learning and instruction: Game-based methods and strategies for training and education. Pfeiffer. Hoboken, NJ.

Lima, Marcos Rodrigues Ornelas de. Videogame e Ensino: a Geografia nos games. Giramundo: Revista de Geografia do Colégio Pedro II, Rio de Janeiro, v. 2, n. 3, p.79-86, 2015.

Mebs, Janice Souza. Gamificação dos Setores da Economia - Uma perspectiva no ensino em Geografia. Repositório Institucional - Ufsc, Joinville, 2017.

Minayo, M. C. S. (Org.). Pesquisa social: teoria, método e criatividade. Petrópolis: Vozes, 2001.

Seixas, L.,R.; Gomes, A. S.; Melo, I. J. Identifying engagement indicators to support educational research. In: Information Systems and Technologies (CISTI), 2015 10th Iberian Conference on. IEEE, 2015. p. 1-6.

Vianna, M.; Vianna, Y.; Adler, I.K; Lucena, B; Russo, B. (2012). “Design Thinking: Inovação em Negócios". Rio de Janeiro: MJV Press.

Vianna, Y., M. Vianna, B. Medina, e S. Tanaka. Gamification, Inc: Como reinventar empresas a partir de jogos. MJV Press, Rio de Janeiro, 2013.

Toda, Armando Maciel; Silva, Yuri Rafael Oliveira; Cruz, Wilmax; Xavier, Luciana; Isotani, Seiji. Um processo de Gamificação para o ensino superior: Experiências em um módulo de Bioquímica. In: Anais do XXII Workshop de Informática na Escola (WIE 2016), p. 495-504. 